\title{
Utilization of Remote Diabetic Retinal Screening in a Suburban Healthcare System
}

\author{
Kristen H Kuo $\mathbb{D}^{1,2}$ \\ Sidrah Anjum' \\ Brian Nguyen 1,3,4 \\ Jeffrey L Marx ${ }^{1,2}$ \\ Shiyoung Roh ${ }^{1,2}$ \\ David J Ramsey (D) ${ }^{1,2}$
}

'Department of Ophthalmology, Lahey Hospital \& Medical Center, Peabody, MA, USA; ${ }^{2}$ Department of Ophthalmology,

Tufts University School of Medicine, Boston, MA, USA; ${ }^{3}$ Tufts University School of Dental Medicine, Boston, MA, USA; ${ }^{4}$ Heller School for Social Policy and Management, Brandeis University, Waltham, MA, USA
Correspondence: David J Ramsey Department of Ophthalmology, Lahey Hospital \& Medical Center, Beth Israel Lahey Health, I Essex Center Drive, Peabody, MA, 01960, USA

Email David.J.Ramsey@lahey.org
Purpose: We conducted a cross-sectional study to assess the utilization of a teleophthalmology screening program in a low-risk, suburban population of patients with diabetes.

Methods: A total of 214 diabetic patients without previously documented diabetic retinopathy (DR) underwent point-of-care non-mydriatic fundus photography through their primary care providers at five Beth Israel Lahey Health locations. The characteristics of the patients who received remote screening were compared with those patients who were eligible for screening but did not take part in the program. Time-driven activity-based costing (TDABC) was implemented to examine the cost of screening by tele-ophthalmology compared with in-person examinations.

Results: Tele-ophthalmology screening was more likely to be provided for patients who were younger (OR $0.985 ; 95 \%$ CI $0.973-0.997, p=0.016$ ), who were obese (OR 2.04; 95\% CI: $1.47-2.84, p=0.008$ ), who had an HbAlc above $8.0 \%$ (OR 1.60; 95\% CI: $1.13-2.26$, $p=0.031$ ), or who had an eye examination in the past year (OR 5.55; 95\% CI: 3.89-7.92, $p<0.001)$. Those patients newly diagnosed with DR because of the program were more likely to have diabetic nephropathy (OR 7.79; 95\% CI: 1.73-35.05, $p=0.007$ ). TDABC identified a health system cost-savings of between $\$ 8$ and $\$ 29$ per patient screened by teleophthalmology compared with the cost of in-person eye examinations.

Conclusion: Tele-ophthalmology presents an opportunity to reduce the costs of screening patients without prior evidence of DR, especially those who have completed a comprehensive eye examination within the prior year.

Keywords: telemedicine, tele-ophthalmology, diabetes, diabetic retinopathy, screening, nonmydriatic fundus photography

\section{Introduction}

More than 34 million Americans have diabetes mellitus, comprising 13\% of the total adult US population. ${ }^{1}$ The number of adults in the US with diagnosed diabetes is projected to nearly triple by $2060 .^{2}$ One of the most disabling complications of diabetes is the development of diabetic retinopathy (DR). Progressive damage to the retinal blood vessels caused by hyperglycemia and other diabetes-associated factors leads to DR. ${ }^{3,4}$ Early detection and treatment of DR is important for preventing vision loss. ${ }^{5}$ As such, regular eye examinations to screen for the initial signs of DR are recommended for all patients with diabetes, ${ }^{6,7}$ but adherence to these guidelines is low despite being covered by health insurance. ${ }^{8-14}$ In especiallyvulnerable populations, rates of annual diabetic eye screening can be as low as $10 \%$ to $30 \% .^{15-17}$ 
Screening for DR has been traditionally performed by means of dilated examination of the fundus by an ophthalmologist or optometrist. More recently, organizations have been incentivized to obtain the equipment and expertise for remote screening through tele-ophthalmology services because of increased insurance coverage for these services, as well as incentives for achieving performance metrics in risk-sharing health insurance contracts. ${ }^{18-20}$ Remote retinal screening is typically performed by using non-mydriatic fundus photography $(\mathrm{nFP})$ at the point-of-care, with the images sent to a trained reader, either an ophthalmologist or optometrist, or an automated retinal image analysis system, to look for signs of diabetic eye disease or other ocular pathology. ${ }^{21-29}$ Because of its high accuracy in monitoring and screening for eye disease, ${ }^{21-24}$ tele-ophthalmology is now considered by the World Health Organization and American Academy of Ophthalmology to be an appropriate tool for population-wide DR screening. ${ }^{30,31}$ Tele-ophthalmology also presents a great opportunity for cost-savings when implemented in appropriate patient populations. ${ }^{27-29,32}$ However, $80-85 \%$ of US ophthalmology practices do not currently provide any teleophthalmology services. ${ }^{33}$

Previous programs employing remote retinal imaging to screen for DR in the US have primarily focused on its use in underserved populations, and as a result, they have reported substantial rates of newly-diagnosed DR. ${ }^{29,34-41}$ To our knowledge, there is no literature assessing the utilization of a tele-ophthalmology program for remote DR screening in a low-risk, well-insured population. In this study, patients with diabetes without DR were invited to undergo point-of-care nFP in a suburban primary care setting to screen for DR. The study evaluates the factors associated with uptake of remote screening and determines the characteristics of patients that are predictive of a positive screening outcome for newly-detected DR.

\section{Methods}

The research followed the tenets of the Declaration of Helsinki and was approved as a quality improvement initiative by the Institutional Review Board of the Lahey Hospital \& Medical Center, Burlington, MA. Information was gathered and secured in compliance with the Health Insurance Portability and Accountability Act. The requirement for informed consent was waived because of the retrospective nature of the study.

\section{Screening Protocol}

Patients with diabetes mellitus without previouslydocumented DR and who were due for annual diabetic eye screening were offered point-of-care remote retinal screening by their primary care physicians (PCPs) between January 2019 and March 2020 across five Lahey Health primary care community practice sites remote to the main hospital. Four sites were equipped with 40-degree Visuscout 100 hand-held cameras (Carl Zeiss Meditec, Inc., Dublin, CA) and one site with a 35-degree tabletop Canon CR2 camera (Canon Inc., Tokyo, Japan) that was shared with a Lahey optometry office. All participants were imaged by means of $\mathrm{nFP}$ by medical assistants trained in the use of the camera systems by ophthalmology staff and under direct supervision of PCPs. Color fundus photographs, centered on the disc and macula, were obtained from each eye through the undilated pupil and sent for review to a board-certified ophthalmologist specializing in retina (DJR). Images were graded for the presence and stage of DR on a color-calibrated liquid crystal display high-resolution monitor. An eye was considered ungradable if the photographic quality and/or media opacity made it impossible to determine if DR lesions were present in the images. Imaging studies were interpreted by the ophthalmologist asynchronously, and the results were returned directly to the PCP. Patients with evidence of DR or other potentially serious eye conditions were referred to ophthalmology by their PCPs for further evaluation. By contrast, patients who were free from signs of DR received letters informing them of their screening results. They were urged to continue annual diabetic eye screenings and to seek in-person eye care for any vision-related issues.

\section{Data Analysis}

Patients who received tele-ophthalmology were compared with those who were eligible for, but did not receive, teleophthalmology services. We evaluated the impact of several readily-obtainable data elements on teleophthalmology uptake and screening outcomes, including age, sex, race, history of tobacco use, type of health insurance, history of nephropathy or neuropathy, systolic and diastolic blood pressure, hemoglobin A1c (HbAlc), low density lipoprotein (LDL), and body mass index (BMI), as well as whether HbA1c, LDL or microalbumin were measured in the last year. We also considered several sociomedical factors, including primary care and ophthalmology appointment history, estimated household income, and distance to the nearest eye clinic. Mean household income by zip code was estimated using 2018 US Census Data for total income divided by the number of 
returns for each zip code. ${ }^{42}$ Each patient's approximate distance to the nearest eye clinic was computed by using an Excel VBA program to access Microsoft Maps which calculated the number of kilometers between each patient's home and clinic by zip code (Microsoft Excel 2010, version 14.0, Microsoft Corporation, Redmond, WA). Using these same variables, patients who were identified to have evidence of DR after tele-ophthalmology screening were also compared with the remainder of patients in the tele-ophthalmology cohort.

\section{Time-Driven Activity-Based Costing}

Time-driven activity-based costing (TDABC) was based on employees working 40 hours per week, with five weeks off, for a total of 1880 hours worked over the course of a year. No adjustment was made for the number of workhours or work-capacity for individual team members. An average salary for each individual team member, based on published data, ${ }^{43-45}$ was divided by this total number of workhours to arrive at an hourly rate. The average time required for an in-person diabetic examination was estimated to be 15 minutes ( 0.25 hours) based on the eye clinic schedule, and the time to complete remote retinal imaging was estimated to take approximately 12 minutes ( 0.2 hours) based on observation of workflow in primary care. Grading of retinal images for each patient was estimated to require less than one minute per eye by an experienced grader (0.03 hours).

\section{Statistical Analysis}

SPSS $^{\circledR}$ Statistics version 27.0 (IBM Corp, Armonk, NY) was used to analyze data. Categorical variables are presented as percentages and compared using the chi-square test. Data for continuous variables was recorded as mean \pm standard deviation (SD) and compared using the Student's $t$-test. Binary logistic regression analysis was used to identify demographic, clinical, and sociomedical factors associated with tele-ophthalmology usage. For the logistic regression of multiple variables, we used a generalized linear model to determine the association between the variables included in the model and tele-ophthalmology status. Odds ratios (ORs) and 95\% confidence intervals (CIs) were calculated for each variable. All tests are 2 -sided, and we consider $p$-values below 0.05 as statistically significant.

\section{Results}

\section{Tele-Ophthalmology Screening}

Out of a total of 1402 patients without previouslydocumented DR, 214 patients (15\%) underwent DR screening with nFP during the period of the program. Of these, 206 participants (96\%) were imaged by means of handheld Visuscout 100 cameras and eight participants (4\%) were imaged using a Canon CR2 camera. Over the course of the study, 14 patients $(7 \%)$ had ungradable photographs submitted in at least one eye. The teleophthalmology program ended March 23, 2020, coinciding with the outbreak of COVID-19 and the stay-at-home advisory ordered by the Governor of Massachusetts. ${ }^{46}$

\section{Demographic, Biometric, and Socioeconomic Factors Predicting Remote Screening}

The mean age of the tele-ophthalmology group was $62.3 \pm 12.5$ years compared with $64.7 \pm 13.8$ years for patients who did not undergo remote screening ( $p=0.014)$. A greater proportion of patients were male in the tele-ophthalmology group compared with the patients who were not screened $\left(74 \%\right.$ versus $63 \%, \chi^{2}=$ $8.90, p=0.003)$. Most patients in the screened and unscreened groups self-identified as white and non-Hispanic (91\% and $91 \%$, respectively, $\left.\chi^{2}=0.0036, p=0.951\right)$. Non-white individuals were screened at a rate proportional to their representation at the primary care sites (OR 1.06; 95\% CI: $0.639-1.77$, $p=0.812$ ). No individual race or ethnicity was screened at a rate different from that expected based on its representation in the study population (Table 1).

HbA1c values were similar in the teleophthalmology group compared with patients who did not undergo remote screening $(7.4 \% \pm 1.7 \%$ versus $7.2 \% \pm 1.5 \%, p=0.115)$. There was also no difference in the HbA1c values between patients who had a priordocumented diabetic eye examination compared with patients for whom no prior eye examination was on record. However, patients with $\mathrm{HbAlc} \geq 8.0 \%$ were more likely to receive tele-ophthalmology (33\% versus 23\%; OR 1.59; 95\% CI: $1.15-2.21, p=0.005)$. Patients who were screened in the tele-ophthalmology program were more likely to have had an HbA1c measurement within the last year (91\% versus $83 \%$, OR 1.97; 95\% CI: $1.20-3.25, p=0.008)$. Those patients were also more likely to be obese $(64 \%$ versus $54 \%$, OR $1.51 ; 95 \%$ CI: $1.12-2.056, p=0.007)$. Other measures 
Table I Characteristics of Patients Who Underwent Remote Screening

\begin{tabular}{|c|c|c|c|c|}
\hline \multirow[t]{2}{*}{ Characteristics } & \multirow{2}{*}{$\begin{array}{l}\text { All Patients } \\
(n=\mid 402)\end{array}$} & \multicolumn{2}{|c|}{ Group } & \multirow[t]{2}{*}{$p$-value ${ }^{\dagger}$} \\
\hline & & $\begin{array}{l}\text { Remote Screening } \\
\qquad(n=2 \mid 4)\end{array}$ & $\begin{array}{l}\text { No Remote Screening } \\
\qquad(n=|| 88)\end{array}$ & \\
\hline \multicolumn{5}{|c|}{ Continuous Variables } \\
\hline \multicolumn{5}{|l|}{ Age (yrs.) } \\
\hline Mean (SD) & $64.4(13.6)$ & $62.3(12.5)$ & $64.7(13.8)$ & 0.014 \\
\hline Median & 65 & 62 & 65 & \\
\hline Range & $19-100$ & $19-95$ & $19-100$ & \\
\hline \multicolumn{5}{|l|}{ HbAlc (\%) } \\
\hline Mean (SD) & $7.3(1.6)$ & $7.4(1.7)$ & $7.2(1.5)$ & 0.115 \\
\hline Median & 6.9 & 6.9 & 6.9 & \\
\hline Range & $4.0-14.0$ & $4.2-13.5$ & $4.0-14.0$ & \\
\hline \multicolumn{5}{|c|}{ Distance to Clinic (miles) } \\
\hline Mean (SD) & $10.6(22.9)$ & $12.9(16.6)$ & $10.2(23.9)$ & 0.372 \\
\hline \multicolumn{5}{|c|}{$\begin{array}{l}\text { Estimated Household Income } \\
\text { (\$ thousands) }\end{array}$} \\
\hline Mean (SD) & $91.5(35.3)$ & $95.1(35.7)$ & $90.8(34.8)$ & 0.112 \\
\hline \multicolumn{5}{|c|}{ Categorical Variables } \\
\hline \multicolumn{5}{|l|}{ Gender (\%) } \\
\hline Male & 65 & 74 & 63 & 0.002 \\
\hline \multicolumn{5}{|l|}{ Type of Diabetes (\%) } \\
\hline Type 2 & 92 & 95 & 92 & 0.064 \\
\hline \multicolumn{5}{|l|}{ Race (\%) } \\
\hline White & 91 & 91 & 91 & 0.809 \\
\hline Asian & 2 & 4 & 2 & 0.086 \\
\hline Black & $<1$ & $<1$ & $<1$ & 0.365 \\
\hline Hispanic & $<1$ & $<1$ & $<1$ & 0.994 \\
\hline Other ${ }^{\S}$ & 5 & 3 & 5 & 0.332 \\
\hline \multicolumn{5}{|l|}{ Insurance Type (\%) } \\
\hline Commercial & 33 & 38 & 32 & 0.089 \\
\hline Medicare & 53 & 44 & 55 & 0.005 \\
\hline Medicaid & 13 & 17 & 12 & 0.056 \\
\hline
\end{tabular}

Notes: Significance is marked in bold $(p<0.05)$. ${ }^{\dagger}$ Statistical analysis was performed between the Remote Screening and No Remote Screening groups. ${ }^{\S}$ Includes individuals self-reporting more than one race.

of metabolic and cardiovascular control showed no statistical difference between the groups, including LDL control $(<100 \mathrm{mg} / \mathrm{dl})$, blood pressure control $(<140 / 90$ $\mathrm{mmHg}$ ), as well as the presence of comorbid end-organ damage, such as peripheral neuropathy and nephropathy (Table 2).

The average distance to the primary care clinic was similar for patients who received tele-ophthalmology screening and those who did not take part in the program
(12.9 \pm 16.6 versus $10.2 \pm 23.9$ miles, $p=0.372)$. However, distance did reduce the likelihood of having a recent primary care visit within the last year (OR 0.992; 95\% CI: $0.986-0.998, p=0.006)$. Estimated mean household income based on each patient's home zip code was also similar for patients who received teleophthalmology screening compared with those who did not participate in the program $(\$ 95,090 \pm \$ 37,665$ versus $\$ 90,842 \pm \$ 34,836, p=0.112)$. 
Table 2 Individual Biometric and Sociomedical Factors Associated with Remote Screening

\begin{tabular}{|c|c|c|c|}
\hline Variable & Remote Screening $(n=214)$ & No Remote Screening $(n=1 \mid 88)$ & $p$-value ${ }^{\dagger}$ \\
\hline Primary Care Office Visit in Last Year & $100 \%$ & $66 \%$ & $<0.001$ \\
\hline Diabetic Eye Exam in Last Year & $73 \%$ & $53 \%$ & $<0.001$ \\
\hline HbAlc Measured in Last Year & $91 \%$ & $83 \%$ & $<0.001$ \\
\hline $\mathrm{HbAlc}<8.0 \%$ & $67 \%$ & $77 \%$ & 0.005 \\
\hline $\mathrm{BP}<140 / 90 \mathrm{mmHg}$ & $81 \%$ & $75 \%$ & 0.086 \\
\hline $\mathrm{LDL}<100 \mathrm{mg} / \mathrm{dL}$ & $65 \%$ & $66 \%$ & 0.703 \\
\hline Obesity (BMI > 30) & $64 \%$ & $54 \%$ & 0.007 \\
\hline Diabetic Nephropathy & $7 \%$ & $10 \%$ & 0.220 \\
\hline Peripheral Neuropathy & $36 \%$ & $33 \%$ & 0.415 \\
\hline Microalbumin Screening in Last Year & $83 \%$ & $79 \%$ & 0.272 \\
\hline
\end{tabular}

Note: ${ }^{\dagger}$ Statistical analysis was performed using $\chi^{2}$ test with significance marked in bold $(p<0.05)$.

Abbreviations: HbAlc, hemoglobin Alc; BP, blood pressure; LDL, low-density lipoprotein level; BMI, body mass index.

Interestingly, patients who underwent teleophthalmology screening were more likely to have had a previous diabetic eye examination in the last year $(73 \%$ versus $\left.53 \%, \chi^{2}=50.553, p<0.001\right)$. This suggests that most patients served by the program had a comparatively low short-term risk for the development of new DR.

\section{Multivariate Regression Analysis for Factors Associated with Tele-Ophthalmology Screening}

Stepwise multiple regression was used to assess which of the identified factors above might influence teleophthalmology screening when combined into a multivariate model. Variables selected for the final model included age, obesity, HbAlc control $(<8.0 \%)$, and completion of an eye examination within the last year (Table 3). Older patients were less likely to receive remote screening (64.7 years versus 62.3 years, OR $0.985 ; 95 \%$ CI: $0.973-0.997, p=0.016)$. Conversely, patients who were obese $(64 \%$ versus $54 \%$,
OR $2.04 ; 95 \%$ CI: $1.47-2.84, p<0.001$ ) or who had an $\mathrm{HbA} 1 \mathrm{c} \geq 8.0 \%(33 \%$ versus $23 \%$, OR $1.60 ; 95 \% \mathrm{CI}$ : $1.13-2.26, p=0.008$ ) were more likely to be screened in the tele-ophthalmology program. However, the strongest predictor of remote imaging was having had an eye examination in the past year ( $73 \%$ versus $53 \%$, OR 5.55 ; 95\% CI: $3.89-7.92, p<0.001)$. Factors excluded were gender, race, type of diabetes, type of insurance, distance to the eye clinic, estimated household income, LDL $(<100 \mathrm{mg} / \mathrm{dl})$ and blood pressure control $(<140 / 90$ $\mathrm{mmHg}$ ), as well as the presence of comorbid end-organ damage, including peripheral neuropathy and nephropathy, owing to a lack of significant unique predictive ability in the stepwise regression.

\section{Detection of Diabetic Retinopathy}

Six patients $(3 \%)$ were newly-diagnosed with more than mild DR as a result of remote screening using handheld, point-of-care cameras in the tele-ophthalmology program. This is similar to the rate of new DR $(2.7 \%)$ recorded

Table 3 Logistic Regression of Multiple Variables Demonstrating Odds of a Patient Receiving Remote Screening

\begin{tabular}{|c|c|c|c|c|c|c|c|}
\hline & \multirow[t]{2}{*}{$\boldsymbol{\beta}$} & \multirow{2}{*}{$\begin{array}{c}\text { Standard } \\
\text { Error }\end{array}$} & \multirow{2}{*}{$\begin{array}{c}\text { Wald } \\
\chi^{2}\end{array}$} & \multirow[t]{2}{*}{$p$-value ${ }^{\dagger}$} & \multirow{2}{*}{$\begin{array}{c}\text { Adjusted } \\
\text { OR }\end{array}$} & \multicolumn{2}{|c|}{$95 \% \mathrm{Cl}$} \\
\hline & & & & & & $\begin{array}{l}\text { Lower- } \\
\text { Bound }\end{array}$ & $\begin{array}{l}\text { Upper- } \\
\text { Bound }\end{array}$ \\
\hline Diabetic Eye Examination in Last Year & 1.713 & 0.181 & 89.263 & $<0.001$ & 5.548 & 3.888 & 7.915 \\
\hline Obesity (BMI > 30) & 0.714 & 0.169 & 17.819 & $<0.001$ & 2.042 & 1.466 & 2.845 \\
\hline $\mathrm{HbAlc} \geq 8.0 \%$ & 0.469 & 0.178 & 6.961 & 0.008 & 1.598 & 1.128 & 2.265 \\
\hline Age & -0.015 & 0.006 & 5.823 & 0.016 & 0.985 & 0.973 & 0.997 \\
\hline
\end{tabular}

Note: ${ }^{\dagger}$ Significance is marked in bold $(p<0.05)$.

Abbreviations: HbAlc, hemoglobin Alc; BMI, body mass index. 
during the study period among patients on the registry maintained by our health system $\left(\chi^{2}=0.072, p=0.789\right)$. Each of these patients were found to have dot and blot hemorrhages in one or both eyes. Follow-up eye examination data was available for five out of the six patients (83\%), which identified moderate non-proliferative diabetic retinopathy (NPDR) in four patients and non-high risk proliferative DR in the fifth. Despite repeated attempts to recall over a six-month period, the sixth patient failed to show up for multiple scheduled appointments.

Of the remaining 195 patients who screened negative for DR in the tele-ophthalmology program, 44 patients (23\%) had routine in-person, follow-up eye examinations negative for DR completed in the year subsequent to their tele-ophthalmology screening; all but one of those examinations occurred before the outbreak of COVID-19. ${ }^{47}$ Of the 14 patients who had screening photographs that were deemed to be of limited quality or ungradable, seven returned for recommended in-person evaluation $(50 \%)$. Three of these seven patients who returned for a comprehensive eye examination after having poorquality images were found to have DR (43\%). Although the outcomes of eye examinations, if any, for the additional seven patients with poor quality images remains unknown because they did not return for eye care within our health system, the rate of DR in this cohort exceeds the rate in the successfully-screened population even if all these additional patients were also free of DR $\left(\chi^{2}=\right.$ $11.10, p<0.001)$. It therefore appears that having images that are of poor or ungradable quality is a potential risk factor for having undiagnosed DR.

Of note, the average $\mathrm{HbA} 1 \mathrm{c}$ level for patients identified with DR was above their goal $(\mathrm{HbAlc}<8.0)$, but this difference did not reach statistical significance when compared with those patients who screened negative for new DR $(8.1 \%$ versus $7.4 \%, p=0.270)$. At these same sites, the
$\mathrm{HbAlc}$ level was higher for the population of patients with known DR, compared with those patients without a history of diagnosed DR $(7.7 \%$ versus $7.2 \%, p=0.003)$. Those patients newly diagnosed with DR because of the program were also more likely to have diabetic nephropathy (33\% versus $6 \%$, OR $7.79 ; 95 \% \mathrm{CI}: 1.73-35.05, p=0.007)$. This too mirrored the prevalence of diagnosed nephropathy for the population of patients with known DR, compared with those without a history of diagnosed retinopathy (OR 3.29; 95\% CI: $2.03-5.20, p<0.001)$. No other biometric or sociomedical factors were significantly associated with newly diagnosed DR.

\section{Cost Analysis}

Using TDABC, we determined that the estimated cost of an in-person dilated eye examination is approximately $\$ 17.64$ when performed by an optometrist $(\$ 71 / \mathrm{hr})$ and $\$ 41.53$ when performed by an ophthalmologist (\$166/ hr). By contrast, acquiring images remotely through our tele-ophthalmology program incurs a cost of $\$ 3.40$ for the labor of the medical assistant and $\$ 4.98$ for a physician to grade a pair of images for a total cost of $\$ 8.38$ per screening. An additional cost would also be incurred when taking into account those patients who either screen positive by teleophthalmology $(3 \%)$ or have uninterpretable images $(7 \%)$. This would require them to follow-up for in-person eye examinations at an estimated cost of between $\$ 1.68$ and $\$ 3.95$ per patient screened depending on whether an optometrist or ophthalmologist performed the in-person examination. This yields a cost-savings of between $\$ 7.58$ and $\$ 29.20$ per patient screened by tele-ophthalmology compared with all patients completing a dilated retinal examination performed by an optometrist or an ophthalmologist, respectively (Table 4).

Table 4 Time-Driven Activity-Based Costing of the Estimated Cost of Implementing Remote Diabetic Retinopathy Screening According to the Personnel Involved

\begin{tabular}{|l|c|c|c|c|c|c|}
\hline & $\begin{array}{c}\text { Required } \\
\text { Personnel }\end{array}$ & $\begin{array}{c}\text { Annual } \\
\text { Salary } \\
\mathbf{( \$ )}\end{array}$ & $\begin{array}{c}\text { Hours } \\
\text { Worked }\end{array}$ & $\begin{array}{c}\text { Wage (\$) } \\
\text { Cost/ } \\
\text { Hour }\end{array}$ & $\begin{array}{c}\text { Time Required to } \\
\text { Complete (Hours) }\end{array}$ & $\begin{array}{c}\text { TDABC/ } \\
\text { Examination } \\
\text { (\$) }\end{array}$ \\
\hline In-person Eye Examination & Ophthalmologist & $299 \mathrm{k}$ & 1800 & 166 & 0.25 & 41.53 \\
In-person Eye Examination & Optometrist & $127 \mathrm{k}$ & 1800 & 71 & 0.25 & 17.64 \\
Remote Screening Examination & Medical Assistant & $\mathrm{N} / \mathrm{A}$ & 1800 & 17 & 0.20 & 3.40 \\
Image Grading & Ophthalmologist & $299 \mathrm{k}$ & 1800 & 166 & 0.03 & 4.98 \\
\hline
\end{tabular}

Abbreviation: TDABC, time-driven activity-based costing. 


\section{Discussion}

This study examined the use of tele-ophthalmology as a screening tool for DR in a low-risk, well-insured suburban population. Several factors were identified as predictive of program participation, including younger age, poorer control of diabetes ( $\mathrm{HbAlc} \geq 8.0 \%$ ), obesity, and having had an eye examination within the last year. Previous studies have demonstrated that older patients with poorer diabetes control, as reflected by higher $\mathrm{HbAlc}$ levels, were more likely to seek ophthalmology services for a yearly eye examination. ${ }^{48,49}$ Older patients may be more likely to need in-person eye examinations because of other comorbid age-related eye conditions. ${ }^{50}$ Our study found that younger patients had higher rates of participation in tele-ophthalmology. A contributing factor may be an unconscious selection bias by providers, with younger patients being easier to image given a lack of media opacities and larger baseline pupil size. ${ }^{51}$ Younger patients may also be more inclined to incorporate telemedicine tools as part of their care. ${ }^{52}$

One of the most striking findings in our study was that patients who had an eye examination within the last year were more likely to be selected for remote diabetic eye disease screening. The rate of diabetic eye screening in our study population is similar to that reported in studies of other high-resource settings. ${ }^{11,38}$ One can speculate that patients who had had recent eye examinations were more knowledgeable about the importance of maintaining eye health and therefore more willing to have their eyes imaged. Providers may have also been more willing to pilot teleophthalmology screening among lower-risk patients who had completed a recent comprehensive eye examination.

Previous reports evaluating screening programs for DR by means of remote retinal imaging in the US have primarily reported on their use in underserved and as yet unscreened populations. As a result, they found significantly higher rates of newly-diagnosed DR, compared with the rate in our study. ${ }^{29,35-41}$ For example, Jani et $\mathrm{al}^{37}$ found that $20.3 \%$ of screened patients had evidence of DR, but those patients lived in rural areas, were mostly non-white, and had not had recent eye examinations. Similarly, Owsley et $\mathrm{al}^{36}$ found that $21.7 \%$ of patients screened positive for DR in a largely uninsured, underserved minority population. Our primary care network serves a largely white, well-insured suburban population with ready access to high-quality health care. As discussed above, one of the strengths of our study is that eye examination results were available in the year preceding tele- ophthalmology screening for the majority of patients in our study. This may have selected patients who had a relatively lower risk of undiagnosed DR. However, the rate of detected DR in our study population (3\%) is similar to the expected yearly incidence of DR among patients with diabetes in the US (3.6\%). ${ }^{53}$ Importantly, none of the patients for whom we have subsequent in-person eye examination data were found to have DR that had been missed by eye screening photographs.

The most widely applied standard of care for screening for DR is a dilated examination of the fundus. When compared with the detection of DR obtained through imaging with seven standard Early Treatment Diabetic Retinopathy Study (ETDRS) fields, a meta-analysis found that the pooled sensitivity of tele-ophthalmology was around $70 \%$ and specificity was around $90 \%$ for most types of $\mathrm{DR}^{22}$ A recent study comparing teleophthalmology using widefield nFP with dilated fundus examinations also found high concordance between the two, with $97.3 \%$ agreement $(\kappa=0.96)$ and $100 \%$ agreement within one step in DR severity. ${ }^{23}$ The handheld Visuscout camera used to screen the majority of patients in our study has a reported sensitivity of $88.7 \%$ to $92.5 \%$ and a specificity ranging from $94.9 \%$ to $96.4 \% .{ }^{24}$ Because of its high specificity, remote fundus photography is a particularly attractive method to reduce the cost of screening patients who are expected to have low rates of DR such as those who have completed a recent healthy eye examination. Even with extended intervals between inperson appointments, such lower-risk patients have been shown to be adherent to subsequent screening visits, with infrequent progression to DR. ${ }^{54-56}$

The projected cost-savings yielded by our teleophthalmology program in our not-for-profit, integrated suburban health system is similar to projections made by other studies that have analyzed remote diabetic retinal screening programs in largely underserved populations. One such study found a cost-savings of $23.3 \%$ for diabetic eye screening conducted by automated widefield nFP provided in the primary care setting as compared with standard dilated retinal examinations. ${ }^{29}$ However, our model does not consider the additional costs of acquiring the necessary training and equipment (i.e. fundus camera) for teleophthalmology or its maintenance. Conversely, we do not account for the significant cost-savings that accrue by preventing disease progression and any associated treatments. $^{32}$ 
The association between newly-detected DR and the presence of diabetic nephropathy in our study comes as no surprise. These two complications are well known to occur together, though there is conflicting evidence about which complication precedes the other. ${ }^{57}$ Nevertheless, our results illustrate the importance of surveilling for DR in patients with other complications caused by diabetes. Another interesting finding was the observation that patients who had poor quality or ungradable images were more likely to be diagnosed with DR. Diabetes is a chronic, degenerative condition and may progressively impact the ocular media or cause pupillary sympathetic denervation, either of which might account for this association.

\section{Limitations}

The limitations of the present study include its retrospective nature and the small sample size derived from a network of outpatient clinics from a single health system. Although providers were asked to refer all eligible patients requiring a diabetic eye examination for teleophthalmology screening, actual referrals were dependent on individual clinical judgment and follow-through. The data available to us is not sufficient to determine which patients were offered tele-ophthalmology or to identify the reasons why some patients may have declined screening. Additionally, we did not control for other comorbid eye diseases that could have influenced patient selection for tele-ophthalmology screening. Whether these were patient- or provider-driven factors cannot be determined by a retrospective review of a clinical program. Our EMR-based program review also misses outcomes from eye care visits that occur outside of our health system. Our study is further limited by the fact that our analysis evaluates the performance of the new screening program over a relatively short period and is unable to directly compare the effectiveness of remote DR screening compared with in-person examinations for all patients. Another important factor contributing to the relatively low number of patients imaged by tele-ophthalmology was staff availability. This was cited by practice managers and medical assistants as the most common reason why more patients were not able to be imaged. Finally, our study does not consider other long-term benefits of remote diabetic retinal screening such as earlier identification of patients at risk of severe vision loss, ${ }^{28,30}$ the potential for increased access to point-of-care testing to enhance patient satisfaction, ${ }^{58}$ or satisfy Healthcare
Effectiveness Data and Information Set (HEDIS) measures necessary for achieving health system quality scores. ${ }^{19}$

\section{Conclusion}

Our study carried out in a suburban, well-insured population of patients found that remote retinal screening most commonly served patients who were at greater risk of not following through with traditional referrals for eye examinations, such as those who are younger, obese, and had poorer metabolic control. ${ }^{8}$ At the same time, teleophthalmology was more commonly utilized to screen patients at lower-risk of having new DR by virtue of having had a recent eye examination without evidence of DR. This represents a potentially more cost-effective and efficient way of screening patients when compared with traditional dilated examinations of the fundus performed by ophthalmologists or optometrists. As the demand for eye care continues to outstrip availability, tele-ophthalmology offers a promising alternative for delivering high-quality, accessible care in a costconscious way.

\section{Abbreviations}

$\mathrm{DR}$, diabetic retinopathy; HbA1c, hemoglobin A1c; nFP, non-mydriatic fundus photography; TDABC, time-drive activity-based costing; HR, Hour; EMR, electronic medical record; PCP, primary care physician; BP, blood pressure; LDL, low-density lipoprotein; BMI, body mass index; OR, odds ratio; CI, confidence interval; SD, standard deviation; NPDR, non-proliferative diabetic retinopathy; COVID-19, coronavirus disease 2019; ETDRS, Early Treatment Diabetic Retinopathy Study; HEDIS, Healthcare Effectiveness Data and Information Set.

\section{Ethical Approval}

This case series was conducted in accordance with the Declaration of Helsinki. The collection and evaluation of all protected patient health information was performed in a HIPAA (Health Insurance Portability and Accountability Act)-compliant manner.

\section{Statement of Informed Consent}

This study received institutional review board approval. A waiver of informed consent was obtained for the research and publication of this article. 


\section{Acknowledgments}

The authors thank Dr. David L. Longworth Dr. Joshua Berkowitz, Dr. Mahesh Bhardwaj, Dr. Ying Jiang, Dr. Joseph Anaya, Dr. Anitha Shelvan, Dr. Peter Speert, Dr. Matthew Lee, Dr. Rebecca Yanovsky, Dr. Raffi Melikian, Dr. Mazhar Kadwalwala, Dr. Nancy Cibotti Granof, Kevin Bennett, David H. Pfennighaus, Karen Latulippe, Donna Marks, David Petalas, Nicholas Repucci, Amanda Lord, Ed Momplaisir, Hilcia M. Downs, Elvira Omerovic, Jerry Chelle, as well as Carol Spencer, Lahey Hospital Librarian, for research support. D.J. Ramsey is the Harry N. Lee Family Chair in Innovation at the Lahey Hospital \& Medical Center, Beth Israel Lahey Health.

\section{Funding}

D.J.R.: Supported by the Harry N. Lee Family Chair in Innovation at the Lahey Hospital \& Medical Center, Beth Israel Lahey Health.

\section{Disclosure}

Manuscript is derived from Annual Meeting Presentation: "Effectiveness of Screening for Diabetic Retinopathy with Teleophthalmology in a Low-Risk Population." Abstract 3535379: Presented at the Assoc. for Research in Vision and Ophthalmology Annual Meeting May 3, 2021. The authors declared no potential conflicts of interest with respect to the research, authorship, and/or publication of this article.

\section{References}

1. Centers for Disease Control and Prevention. National diabetes statistics report, 2020. Atlanta, GA: Centers for Disease Control and Prevention, U.S. Dept. of Health and Human Services; 2020. Available from: https://www.cdc.gov/diabetes/pdfs/data/statistics/ national-diabetes-statistics-report.pdf. Accessed October 30, 2020.

2. Lin J, Thompson TJ, Cheng YJ, et al. Projection of the future diabetes burden in the United States through 2060. Popul Health Metr. 2018;16 (1):9. doi:10.1186/s12963-018-0166-4

3. Aiello LP, Cahill MT, Wong JS. Systemic considerations in the management of diabetic retinopathy. Am J Ophthalmol. 2001;132 (5):760-776. doi:10.1016/S0002-9394(01)01124-2

4. Ramsey DJ, Arden GB. Hypoxia and dark adaptation in diabetic retinopathy: interactions, consequences, and therapy. Curr Diab Rep. 2015;15(12):118. doi:10.1007/s11892-015-0686-2

5. Centers for Disease Control and Prevention. Vision Health Initiative (VHI). Tips to prevent vision loss. Division of Diabetes Translation, National Center for Chronic Disease Prevention and Health Promotion; 2019. Available from: https://www.cdc.gov/visionhealth/ risk/tips.htm. Accessed January 28, 2021.

6. Solomon SD, Chew E, Duh EJ, et al. Diabetic retinopathy: a position statement by the American Diabetes Association. Diabetes Care. 2017;40(3):412-418.9. doi:10.2337/dc16-2641
7. Flaxel CJ, Adelman RA, Bailey ST, et al. Diabetic retinopathy preferred practice pattern ${ }^{\circledR}$. Ophthalmology. 2020;127(1):P66-P145.

8. Keenum Z, McGwin G, Witherspoon CD, Haller JA, Clark ME, Owsley C. Patients' adherence to recommended follow-up eye care after diabetic retinopathy screening in a publicly funded county clinic and factors associated with follow-up eye care use. JAMA Ophthalmol. 2016;134(11):1221-1228. doi:10.1001/jamaophthalmol.2016.3081

9. Gibson AA, Humphries J, Gillies M, Nassar N, Colagiuri S. Adherence to eye examination guidelines among individuals with diabetes: an analysis of linked health data. Clin Exp Ophthalmol. 2020;48(9):1229-1238. doi:10.1111/ceo.13830

10. Gange WS, Xu BY, Lung K, Toy BC, Seabury SA. Rates of eye care and diabetic eye disease among insured patients with newly diagnosed type 2 diabetes. Ophthalmol Retina. 2021;5(2):160-168. doi:10.1016/j.oret.2020.07.004

11. Klein R, Klein BE. Screening for diabetic retinopathy, revisited. Am $J$ Ophthalmol. 2002;134(2):261-263. doi:10.1016/S0002-9394(02) 01593-3

12. Lundeen EA, Wittenborn J, Benoit SR, Saaddine J. Disparities in receipt of eye exams among Medicare Part B fee-for-service beneficiaries with diabetes - United States, 2017. MMWR Morb Mortal Wkly Rep. 2019;68(45):1020-1023. doi:10.15585/mmwr.mm6845a3

13. Judah G, Vlaev I, Gunn L, et al. Incentives in Diabetic Eye Assessment by Screening (IDEAS): study protocol of a three-arm randomized controlled trial using financial incentives to increase screening uptake in London. BMC Ophthalmol. 2016;16:28. doi:10.1186/s12886-016-0206-4

14. Riordan F, Racine E, Phillip ET, et al. Development of an intervention to facilitate implementation and uptake of diabetic retinopathy screening. Implement Sci. 2020;15(1):34. doi:10.1186/s13012-02000982-4

15. Daskivich LP, Vasquez C, Martinez C, Tseng CH, Mangione CM. Implementation and evaluation of a large-scale teleretinal diabetic retinopathy screening program in the Los Angeles County Department of Health Services. JAMA Intern Med. 2017;177 (5):642-649. doi:10.1001/jamainternmed.2017.0204

16. Kuo J, Liu JC, Gibson E, et al. Factors associated with adherence to screening guidelines for diabetic retinopathy among low-income metropolitan patients. Mo Med. 2020;117(3):258-264.

17. Leese GP, Boyle P, Feng Z, Emslie-Smith A, Ellis JD. Screening uptake in a well-established diabetic retinopathy screening program: the role of geographical access and deprivation. Diabetes Care. 2008;31(11):2131-2135. doi:10.2337/dc08-1098

18. Centers for Medicare and Medicaid Services. Current medicare coverage of diabetes supplies; 2021. Available from: https://www.cms. gov/Outreach-and-Education/Medicare-Learning-Network-MLN /MLNMattersArticles/Downloads/SE18011.pdf\#: :text=Medicare\% 20covers $\% 20$ certain $\% 20$ supplies $\% 20$ if $\% 20 \mathrm{a} \% 20$ beneficiary $\% 20$ has, pumps $\% 20$ and $\% 20$ the $\% 20$ insulin $\% 20$ used $\% 20$ in $\% 20$ the $\% 20$ pumps. Accessed July 19, 2021.

19. Calman NS, Hauser D, Chokshi DA. "Lost to follow-up": the public health goals of accountable care. Arch Intern Med. 2012;172 (7):584-586. doi:10.1001/archinternmed.2012.219

20. Fatehi F, Jahedi F, Tay-Kearney ML, Kanagasingam Y. Teleophthalmology for the elderly population: a review of the literature. Int $J$ Med Inform. 2020;136:104089. doi:10.1016/j. ijmedinf.2020.104089

21. Silva PS, Cavallerano JD, Sun JK, Noble J, Aiello LM, Aiello LP. (2012): nonmydriatic ultrawide field retinal imaging compared with dilated standard 7-field 35-mm photography and retinal specialist examination for evaluation of diabetic retinopathy. Am J Ophthalmol. 2012;154(3):549-559.e2. doi:10.1016/j.ajo.2012.03.019

22. Shi L, Wu H, Dong J, Jiang K, Lu X, Shi J. Telemedicine for detecting diabetic retinopathy: a systematic review and meta-analysis. Br J Ophthalmol. 2015;99(6):823-831. doi:10.1136/ bjophthalmol-2014-305631 
23. Borrelli E, Querques L, Lattanzio R, et al. Nonmydriatic widefield retinal imaging with an automatic white LED confocal imaging system compared with dilated ophthalmoscopy in screening for diabetic retinopathy. Acta Diabetol. 2020;57(9):1043-1047. doi:10.1007/s00592-020-01520-w

24. Piyasena MMPN, Yip JLY, MacLeod D, Kim M, Gudlavalleti VSM. Diagnostic test accuracy of diabetic retinopathy screening by physician graders using a hand-held non-mydriatic retinal camera at a tertiary level medical clinic. BMC Ophthalmol. 2019;19(1):89. doi:10.1186/s12886-019-1092-3

25. Tufail A, Rudisill C, Egan C, et al. Automated diabetic retinopathy image assessment software: diagnostic accuracy and cost-effectiveness compared with human graders. Ophthalmology. 2017;124(3):343-351. doi:10.1016/j.ophtha.2016.11.014

26. Bhaskaranand $\mathrm{M}$, Ramachandra $\mathrm{C}$, Bhat $\mathrm{S}$, et al. Automated diabetic retinopathy screening and monitoring using retinal fundus image analysis. J Diabetes Sci Technol. 2016;10(2):254-261. doi:10.1177/ 1932296816628546

27. Avidor D, Loewenstein A, Waisbourd M, Nutman A. Costeffectiveness of diabetic retinopathy screening programs using telemedicine: a systematic review. Cost Eff Resour Alloc. 2020;18:16. doi:10.1186/s12962-020-00211-1

28. Ullah W, Pathan SK, Panchal A, et al. Cost-effectiveness and diagnostic accuracy of telemedicine in macular disease and diabetic retinopathy: a systematic review and meta-analysis. Medicine. 2020;99(25):e20306. doi:10.1097/MD.0000000000020306

29. Fuller SD, Hu J, Liu JC, et al. Five-year cost-effectiveness modeling of primary care-based, nonmydriatic automated retinal image analysis screening among low-income patients with diabetes. J Diabetes Sci Technol. 2020;193229682096701. doi:10.1177/1932296820967011

30. Rodríguez Villa S, Alonso Álvarez C, de Dios Del Valle R, et al. Five-year experience of tele-ophthalmology for diabetic retinopathy screening in a rural population. Arch Soc Esp Oftalmol. 2016;91 (9):426-430. doi:10.1016/j.oftal.2016.01.023

31. World Health Organization Regional Office for Europe. Diabetic retinopathy screening: a short guide; 2020. Available from: https:// www.euro.who.int/en/publications/abstracts/diabetic-retinopathyscreening-A-short-guide-2020. Accessed August 17, 2021.

32. Garoon RB, Lin WV, Young AK, Yeh AG, Chu YI, Weng CY. Cost savings analysis for a diabetic retinopathy teleretinal screening program using an activity-based costing approach. Ophthalmol Retina. 2018;2(9):906-913. doi:10.1016/j.oret.2018.01.020

33. Starr MR, Israilevich R, Zhitnitsky M, et al. Practice patterns and responsiveness to simulated common ocular complaints among US ophthalmology centers during the COVID-19 pandemic. JAMA Ophthalmol. 2020;138(9):981-988. doi:10.1001/jamaophthalmol.2020.3237

34. Aleo CL, Murchison AP, Dai Y, et al. Improving eye care follow-up adherence in diabetic patients with ocular abnormalities: the effectiveness of patient contracts in a free, pharmacy-based eye screening. Public Health. 2015;129(7):996-999. doi:10.1016/j.puhe.2015.05.012

35. Gu D, Agron S, May LN, Mirza RG, Bryar PJ. Nonmydriatic retinal diabetic screening in the primary care setting: assessing degree of retinopathy and incidence of nondiabetic ocular diagnoses. Telemed $J$ E Health. 2020;26(10):1252-1256. doi:10.1089/tmj.2019.0206

36. Owsley C, McGwin G, Lee DJ, et al. Diabetes eye screening in urban settings serving minority populations: detection of diabetic retinopathy and other ocular findings using telemedicine. JAMA Ophthalmol. 2015;133(2):174-181. doi:10.1001/jamaophthalmol.2014.4652

37. Jani PD, Forbes L, Choudhury A, Preisser JS, Viera AJ, Garg S. Evaluation of diabetic retinal screening and factors for ophthalmology referral in a telemedicine network. JAMA Ophthalmol. 2017;135 (7):706-714. doi:10.1001/jamaophthalmol.2017.1150

38. Martinez JA, Parikh PD, Wong RW, et al. (2019): telemedicine for diabetic retinopathy screening in an urban, insured population using fundus cameras in a primary care office setting. Ophthalmic Surg Lasers Imaging Retina. 2019;50(11):e274-e277. doi:10.3928/ 23258160-20191031-14
39. Chin EK, Ventura BV, See KY, Seibles J, Park SS. Nonmydriatic fundus photography for teleophthalmology diabetic retinopathy screening in rural and urban clinics. Telemed $J$ E Health. 2014;20 (2):102-108. doi:10.1089/tmj.2013.0042

40. Toy BC, Aguinaldo T, Eliason J, Egbert J. Non-mydriatic fundus camera screening for referral-warranted diabetic retinopathy in a northern California safety-net setting. Ophthalmic Surg Lasers Imaging Retina. 2016;47(7):636-642. doi:10.3928/23258160-20160707-05

41. Tsui I, Havunjian MA, Davis JA, Giaconi JA. Snapshot of teleretinal screening for diabetic retinopathy at the West Los Angeles Medical Center. Telemed J E Health. 2016;22(10):843-846. doi:10.1089/ tmj.2015.0246

42. Internal Revenue Service. SOI tax stats - individual income tax statistics - ZIP code data (SOI); 2021. Available from: https://www. irs.gov/statistics/soi-tax-stats-individual-income-tax-statistics-zipcode-data-soi. Accessed April 6, 2021.

43. Salary.com. Physician-ophthalmology salary in the United States. Available from: https://www.salary.com/research/salary/benchmark/ opthalmologist-salary. Accessed January 28, 2021.

44. Salary.com. Optometrist salary in the United States. Available from: https://www.salary.com/research/salary/benchmark/optometristsalary. Accessed January 28, 2021.

45. Salary.com. Hourly wage for medical assistant salary in the United States. Available from: https://www.salary.com/research/salary/bench mark/medical-assistant-hourly-wages. Accessed January 28, 2021.

46. Commonwealth of Massachusetts. Press release: Baker-Polito administration announces emergency actions to address COVID-19; 2020. Available from: https://www.mass.gov/news/baker-politoadministration-announces-emergency-actions-to-address-covid-19. Accessed April 28, 2020.

47. Shih KC, Kwong ASK, Wang JHL, et al. Diabetic retinopathy screening during the coronavirus disease 2019 pandemic. Eye (Lond). 2020;34(7):1246-1247. doi:10.1038/s41433-020-0928-7

48. An J, Niu F, Turpcu A, Rajput Y, Cheetham TC. Adherence to the American Diabetes Association retinal screening guidelines for population with diabetes in the United States. Ophthalmic Epidemiol. 2018;25(3):257-265. doi:10.1080/09286586.2018.1424344

49. Eppley SE, Mansberger SL, Ramanathan S, Lowry EA. Characteristics associated with adherence to annual dilated eye examinations among US patients with diagnosed diabetes. Ophthalmology. 2019;126(11):1492-1499. doi:10.1016/j.ophtha.2019.05.033

50. Klein R, Klein BE. The prevalence of age-related eye diseases and visual impairment in aging: current estimates. Invest Ophthalmol Vis Sci. 2013;54(14):ORSF5-ORSF13. doi:10.1167/iovs.13-12789

51. Telek HH, Erdol H, Turk A. The effects of age on pupil diameter at different light amplitudes. Beyoglu Eye J. 2018;3(2):80-85.

52. Mikulic M. Willingness to use telehealth among adults in the U.S. 2019, by age. Statista.com; 2020. Available from: https://www.sta tista.com/statistics/1189987/willingness-use-telehealth-among-adultsby-age-us/. Accessed June 2, 2021.

53. Sabanayagam C, Banu R, Chee ML, et al. Incidence and progression of diabetic retinopathy: a systematic review. Lancet Diabetes Endocrinol. 2019;7(2):140-149. doi:10.1016/S2213-8587(18)30128-1

54. Sharif A, Jendle J, Hellgren KJ. Screening for diabetic retinopathy with extended intervals, safe and without compromising adherence: a retrospective cohort study. Diabetes Ther. 2021;12(1):223-234. doi:10.1007/s13300-020-00957-0

55. Conlin PR, Fisch BM, Cavallerano AA, Cavallerano JD, Bursell SE, Aiello LM. Nonmydriatic teleretinal imaging improves adherence to annual eye examinations in patients with diabetes. $J$ Rehabil Res Dev. 2006;43(6):733-740. doi:10.1682/JRRD.2005.07.0117

56. Fonda SJ, Bursell SE, Lewis DG, Garren J, Hock K, Cavallerano J. The relationship of a diabetes telehealth eye care program to standard eye care and change in diabetes health outcomes. Telemed J E Health. 2007;13(6):635-644. doi:10.1089/tmj.2007.0025 
57. Pearce I, Simó R, Lövestam-Adrian M, Wong DT, Evans M. Association between diabetic eye disease and other complications of diabetes: implications for care. A systematic review. Diabetes Obes Metab. 2019;21(3):467-478. doi:10.1111/dom.13550
58. Patzer KH, Ardjomand P, Göhring K, et al. Implementation of HbAlc point of care testing in 3 German medical practices: impact on workflow and physician, staff, and patient satisfaction. J Diabetes Sci Technol. 2018;12(3):687-694. doi:10.1177/1932296818759690

\section{Publish your work in this journal}

Clinical Ophthalmology is an international, peer-reviewed journal covering all subspecialties within ophthalmology. Key topics include: Optometry; Visual science; Pharmacology and drug therapy in eye diseases; Basic Sciences; Primary and Secondary eye care; Patient Safety and Quality of Care Improvements. This journal is indexed on PubMed

Submit your manuscript here: https://www.dovepress.com/clinical-ophthalmology-journal
Central and CAS, and is the official journal of The Society of Clinical Ophthalmology (SCO). The manuscript management system is completely online and includes a very quick and fair peer-review system, which is all easy to use. Visit http://www.dovepress.com/ testimonials.php to read real quotes from published authors. 